\title{
An Overview of Wild Edible Fungi Resource Conservation and Its Utilization in Yunnan
}

\author{
Rong Hua ${ }^{1,3}$, Zhen $\mathrm{Chen}^{2} \&$ Wen $\mathrm{Fu}^{4}$ \\ ${ }^{1}$ Acadamic Institute of Yunnan Federation of Supply and Marketing Cooperative, Kunming, China \\ ${ }^{2}$ College of Resource and Environment, Yuxi Normal University, Yuxi, China \\ ${ }^{3}$ Kunming Edible Fungi Institute of All China Federation of Supply and Marketing Cooperatives, Kunming, \\ China \\ ${ }^{4}$ Plant conservation and Quarantine Station of Yunnan Province, Kunming, China \\ Correspondence: Zhen Chen, College of Resource and Environment, Yuxi Normal University, Yuxi, NO., 134 \\ Fenghuang Road, China. Tel: 1-388-813-8791. E-mail: cz@yxnu.net
}

Received: January 21, $2017 \quad$ Accepted: March 22, $2017 \quad$ Online Published: April 15, 2017

doi:10.5539/jas.v9n5p158 URL: https://doi.org/10.5539/jas.v9n5p158

\begin{abstract}
As one of the province with the most abundant bio-diversity in China, Yunnan is also one of the most-concerned region in the world which is famous for its bio-diversity. The wild edible fungi resources in Yunnan are extremely rich and diverse, which account for nearly $40.7 \%$ of the world's known resources and $90 \%$ of China's known resource respectively. Serving as one important type of forest understory resource and product, the wild edible fungi has a large market due to its unique flavor, texture or special health care function. Therefore, sustainable utilization of the wild edible fungi resource is of paramount importance to develop the rural livelihood and furthermore conserve forest and animal resources in Yunnan. Integrating a large number of previous researches, this paper has summarized the current situations of edible fungi resources as well as the existing problems on production, food, medicine utilization, processing, trade and resource conservation inYunnan. Data showed that the wild edible fungi resources are playing extremely important roles on the peasant household incomes in the vast mountainous areas in Yunnan. For example, the fungi collection incomes can account for $50 \%$ to $80 \%$ of the household income in Xishuangbanna. However, the wild edible fungi resources are facing the problems of the reductions in resource types and quantities, unclear ownership, improper collection and conservation measures, unscientific management as well as other outstanding issues. The author point out that it is quite essential to clear the ownership, implement the community-based conservation strategies as well as to strengthen the researches on the scientific collection, conservation and breeding technologies in order to solve the problems in the effective conservation and sustainable utilization of the wild edible fungi resources in the future.
\end{abstract}

Keywords: edible fungi, forest resources, bio-diversity, sustainable utilization, conservation

\section{Introduction}

As one of the province with the most abundant bio-diversity in China, the rare species number in Yunnan have account for nearly $67.5 \%$ in China, ranking the first in the whole country, which is also one of the mostconcerned region in the world famous for its bio-diversity. Taking the higher plants and the vertebrates as examples, they account for $45.9 \%$ and $55.4 \%$ in China respectively (Chen et al., 2010). In addition, more than $80 \%$ of Yunnan's bio-diversities are found to be existing in the forests, therefore it is of great significance to protect the forests in Yunnan for the benefits of the bio-diversity conservation, the water environment and the climate environment (Jia, 2003).

However, protecting forests or conserving bio-diversities are discovered to be in conflicts with the community economic developments in most cases. The driving force of economic development leads to the destruction of forests and bio-diversities frequently (D. Zhang \& X. S. Zhang, 2013). Therefore, seeking for the sustainable development approaches of the environmental as well as the climate-friendly rural economy are critical strategies for the conservation of forests and bio-diversities. 
Yunnan is abundant in the edible fungi resources, whose known wild edible fungi species can account for nearly $44.1 \%$ of the world and the resource storage capacity can reach 0.5 million tons/year (Yu, 2002). In addition, the wild edible fungi has a large market due to its unique flavor, texture or special health care function (Pavel, 2009; Mirian, 2010), only the annual trading quantities of truffles, Tricholoma matsutakes, Boletus edulis and Chanterelles have reached 0.306 million tons and the trading volume have reached 2.87 billion dollars around the world (Xiong, 2014). As a type of forest product with important economic value, wild edible fungi occupies considerable proportions on the peasant household incomes in the vast mountainous areas in Yunnan (Lv et al., 2007; Yang, 2008; Xu et al., 2014). Therefore, how to make good use of the edible fungi in a sustainable approach and to raise the economic incomes of the peasant households in rural communities have become one of the critical measures to protect the forests as well as the bio-diversities in the vast rural areas of Yunnan. Based on a large number of research literature, this paper has analyzed the current situation of edible fungi resources as well as the existing problems on production, food, medicine utilization, processing, trade and resource conservation in Yunnan. Moreover, the strategies of the sustainable utilization and effective conservation for the wild edible fungi have also been discussed in this paper in order to provide effective references for the sustainable utilization and conservation of the wild edible fungi resource as well as to provide lessons for the conflict coordination between the community economic development and forest's bio-diversity conservation.

\section{Current Utilization Status of Wild Edible Fungi Resources}

\subsection{Wild Edible Fungi Species}

The edible fungi specie resource in Yunnan is abundant. There are a total of 882 pieces of edible fungi in the whole province, which belongs to 2 phyla, 5 classes, 13 orders, 54 families and 161 genera, accounting for $40.7 \%$ in the world and $90 \%$ in China respectively. Among them, there are 526 species of Agaricales, accounting for $80.4 \%$ of the total number of the Agaricales in China; There are 227 species of Polyporales, which are 62 species more than the national statistics of the 165 species. There are 58 species of Ascomycetes, accounting for $89.1 \%$ of the total number of the Ascomycetes in China; There are 20 species of Gelatinous fungus, including all kinds of the known species in China; There are 62 species of Gasteromycetes, accounting for $68 \%$ of the total number of the Gasteromycetes in China. According to the fertility nutrition types, there are about 200 pieces of saprophytic bacteria and about 700 species of symbiotic bacteria (Zhang, 1984; Gui \& Xu, 1999; Research Group of Wild Edible Fungi in Yunnan, 2016). Moreover, the function of the edible fungi resource in Yunnan is diverse. Some of them also possess the medicinal values in addition to the edible values, and there are about 200 species of the multi-functional edible fungi with both the edible and medicinal values, accounting for $22.7 \%$ (Dai et al., 2013). In addition, the edible fungi forest resource in Yunnan is also diverse. There are 371 million mu forestry lands in Yunnan, with forest coverage of 55.7\%, and there are more than 90 kinds of symbiotic plant species of edible fungi, including dark coniferous forests, rhododendron forests, oak forests, pine forests and other forest vegetation (Zhang, 1999), which createfavorable conditions for the growth and reproduction of the wild fungi. In an investigation on the wild edible fungi resource situations of the pine forests in central Yunnan and its adjacent areas, Yu and Liu (2005) found that there were 27 families, 39 genera and 147 edible fungi species growing up under the pine forests in Yunnan. In recent years, some scholars have successively investigated the wild edible fungus resources in Pu'er City, and 38 families, 67 genera and 155 species were found successively: about 67 edible fungi species were found growing up in the tropical seasonal rain forest and the mountain rain forest, about 29 edible fungi species were found growing up in the warm bamboo forest, about 83 edible fungi species were found growing up in the monsoon evergreen broad-leaved forest, about 34 edible fungi species were found growing up in the middle mountain moist evergreen broad-leaved forest, about 75 edible fungi species were found growing up in the warm coniferous forest, and about 13 edible fungi species were found growing up in the warm temperate coniferous forest (Tong, 2010; Yu \& Liu, 2013). The wild edible fungi resources are widespread in the 129 counties and cities in the whole province. Moreover, Chuxiong is the region with the most abundant edible fungi resources in Yunnan, which possesses more than 450 species of edible fungi, followed by Kunming, with about 400 species, Qujing and Yuxi possess more than 300 species of edible fungi respectively, Baoshan, Lijiang, Lincang, Dali, Nu River, Diqing and other places process between 200 to 300 edible fungi species. Besides, four world's famous bacteria, Tricholoma matsutakes, Boletus, truffles and Chanterelles are scattered around Yunnan with relatively large amounts of resources compared with other regions (Research Group of Wild Edible Fungi in Yunnan, 2016).

\subsection{Production and Processing}

Artificial or imitating wild condition is one of the main aspects of the conservation and production of wild edible fungi. $62.1 \%$ of the edible fungi products in Yunnan belong to the artificial or imitating wild-cultivated edible fungi (Yu et al., 2002). The main cultivated varieties include the following more than 20 species: Pleurotus 
ostreatus, Lentinula edodes, black fungus, Flammulina velutipes, Agrocybe cylindracea, Pleurotus eryngii, Ganoder malucidum, Phlebopus portentosus, Morchella vulgaris and others (Su et al., 2006; Research Group of Wild Edible Fungi in Yunnan, 2016). Produce and process the fresh products, frozen products, fried products, dry products, salted products, cans, beverages, wines, condiments, noodles, health care products, flavor foods and other products (Xu \& Gui, 1998; Xiong, 2014). In order to improve the product qualities, 341 national, industrial, local and enterprise standards on the production, processing, packaging, transportation, distribution and sale have been developed so as to standardize the production and operation activities (Research Group of Wild Edible Fungi in Yunnan, 2016), to ensure that the processing, packaging, transportation, distribution and sale processes in the edible fungi industry in Yunnan can reach the standards in the developed countries, as well as to effectively deal with the technical and trade barriers faced by the export of edible fungi (Luan, 2010). Natural growing and free collection are the other main aspects of the production of wild edible fungi. $37.9 \%$ of the edible fungi products come from the natural growths, free picking, collections as well as processing. The varieties of the naturally grew edible fungi are quite diversified, accounting for more than $90 \%$ of the wild edible fungi resources, such as the Tricholoma matsutake, Boletus, Termitomyces albuminosus, Russula virescens, Lactarius deliciosus and Cordyceps sinensis, which are all very common varieties (Yu, 2002). At present, these species can not be cultivated artificially or be cultivated by imitating the wild conditions, which are mostly picked and sold freely by the people in mountain areas. Despite the great tastes, the qualities are at various levels, and the products are mainly focused on the fresh products, frozen products, fried products, dry products, salted product and cans at the primary processing levels due to the strong seasonal features (Gui \& Xu, 1999). During the "12th Five-Year Plan" period, Yunnan strove to develop the edible fungi industry, forming 400 cooperatives and 532 enterprises which are engaged in the production, processing and marketing of edible fungi, constructing 32 edible fungi base counties with the total area of 5.68 million square meters and the total yield of about 0.1 million tons, establishing 142 wild edible fungi conservation and cultivation bases, which stabilize and increase the natural production of wild edible fungi (Yunnan Provincial Department of Agriculture, 2016). In 2015, the total yield of edible fungi in the whole province (fresh products) reached 0.449 million tons, of which: 0.17 million tons of wild edible fungi yield and 0.279 million tons of cultivated edible fungi yield (Research Group of Wild Edible Fungi in Yunnan, 2016).

\subsection{Food Utilization}

Wild edible fungi has low fat, low energy and high protein, which is also abundant in dietary fibers, vitamins, organic acids and minerals (Pavel, 2009; Wang et al., 2014). In general, the water accounts for between $85 \%$ to $95 \%$ in the fresh weight of the wild edible fungi, protein content is between $16 \%$ to $35 \%$, carbohydrate content is between $28 \%$ to $39.9 \%$, and fat content is between $2 \%$ to $6 \%$, containing $\mathrm{Cu}, \mathrm{Fe}, \mathrm{K}, \mathrm{Mg}, \mathrm{Se}, \mathrm{P}, \mathrm{Zn}$ and other essential elements required by the human body ( $\mathrm{Na}$ content is extremely low in wild edible fungi), being rich in oleic acids, linoleic acids and other unsaturated fatty acids, as well as containing abundant vitamins (including vitamin $\mathrm{A}, \mathrm{B}, \mathrm{C}, \mathrm{D}$ and $\mathrm{K}$ ), these characteristic determine the wild edible fungi to be an excellent healthy eating product (Mirian, 2010). Besides, Yunnan people are fond of eating wild fungi. The wild edible fungi delicacies can be made through stir frying, cooking, baking, frying and other cooking methods, which can also be stored for a long time in preparation for eating or trading by freezing, salting, drying (baking), frying and other simple processing. Moreover, wild edible fungi is considered as an important source of food to improve the health levels for the people in remote poverty-stricken areas, which is also a kind of delicacy for the people living in the city area. Tricholoma matsutake, Termitomyces albuminosus, Boletus, Russula virescens, Lactarius deliciosus, Lentinula edodes and fungus are common food varieties in Yunnan (Wang \& Liu, 2002). Food consumption is one major aspect of the wild edible fungi utilization, the estimated per capita consumption in the consumer group can reach $1 \mathrm{Kg} /$ year due to the difficulty in counting the self-eating number. At the same time, the wild fungi catering industry has experienced a vigorous development in the past several years. In 2015, there were 2,128 edible fungi catering enterprises throughout the whole province, realizing operating income of up to 0.9 billion Yuan according the statistical data (Yunnan Provincial Department of Agriculture, 2016). Besides, health food development is the other major aspect of the wild edible fungi utilization. At present, there are about 300 health food products registered and approved by the State Food and Drug Administration and the Ministry of Health, mainly focusing on the series products which are developed by Ganoder malucidum, fungus, Hericiumer inaceus, Tremella and other raw materials (Luo et al., 2011).

\subsection{Drug Utilization}

Wild edible fungi contains fungi polysaccharides, dietary fibers, lectins, alkaloids, phenolic compounds, sphingolipids, pigments, steroids, terpenoids, glycoproteins, nucleic acids, proteins, organic acids, polyols, furan derivatives, trace elements, vitamins and other functional active substances, which can prevent tumor, regulate 
immunity, treat and prevent the cardiovascular disease, reduce the blood fat and the cholesterol, protect the liver, treat diabetes, slow down aging, prevent viruses and bacteria, kill insects and other functions, as well as possess the potential for the development of new drug (Wang, 2001; Zhao et al., 2013). However, the development of wild edible fungi in Yunnan is still in its primary stage. Firstly, the product types of wild edible fungi are limited, such as capsules, oral liquids, polysaccharide extracts, health care wines and other types. In addition, there are only 50 species have been commercialized up till now, mainly including polysaccharopeptide, yunzhigantai electuary (or granules), Polyporus umbellatus polysaccharide injections (or tablets), lentinan polysaccharide injections (or tablets), Halimasch capsules, Hericium erinaceus tablets (or oral liquids), Ganoderma lucidum capsules, Ganoderma lucidum spore powder capsules, silver spore syrups, ergometrinemaleate injections, Rhodiola, Cordyceps capsules, Paecilomyces hepiall, wuling capsules, brauncapsules, Ganoderma capense tablets, jisheng injections, coronary tablets, nephritis capsules, Cordyceps cephalosporium mycelia capsules, fragrant tablets, lentinan injections and so on (Zhang, 1994; Xu \& Gui, 1998; Luo et al., 2011). Secondly, the scale of processing is relatively small, and the deep processing is not enough. Nowadays, the processing of wild edible fungi has been limited to the manufactures of Chinese traditional patent medicines, the extractions of intermediate raw materials and the processing of traditional Chinese medicine decoction pieces (Luo et al., 2011). Some functional factors of these Chinese traditional patent medicines are not yet clear, which not only consume large resources but also require great efforts on the product quality controls. Thirdly, the types of resources for drug development are still limited. There are about 200 kinds of wild edible fungi which are able to produce antibiotics, and there are more than 100 kinds of fungi metabolic products found to be possessed with strong anti-tumor activities (Zhao et al., 2013). However, the experimental studies or primary processing on the medicinal values have only been carried out for the Cordyceps sinensis, Ganoderma lucidum, Lentinula edodes, Trametes versicolor, Agaricus brasiliensis, Collybia velutipes, Grifola frondosa, Schizophyllum commune, Wolfiporia cocos, Hericiumer inaceus, Poria cocos, Polyporus umbellatus, Tremella, Hericium erinaceus, Cordyceps militaris, Morchella vulgaris (Zhang, 1994; Xu \& Gui, 1998; Luo et al., 2011), and a large amount of resources are still remained to be available for further explorations.

\subsection{Product Utilization}

The wild edible fungi products produced in Yunnan are mainly sold in the domestic market and the foreign market, of which the domestic sales account for $70.4 \%$ of the total wild fungi product resources in Yunnan (see more details in Tables 1-3). The peasants in mountain area collect and sell the fresh products or dry products made of wild edible fungi, while the collection incomes vary from region to region. For example, the fungi collection incomes can account for $50 \%$ to $80 \%$ of the household income in Xishuangbanna, 5\% to $7 \%$ in Wuding County, and only $1.2 \%$ to $3.0 \%$ of the total income of the peasant household in Yimen County (Peng et al., 2002; Yang, 2008; Xu et al., 2014). Traders, cooperatives and enterprises purchase, process and sell the fresh products, dry products, salted products, fried products, cans, drugs and cosmetics and other products which are made from wild fungi (Yunnan Provincial Department of Agriculture, 2016). During the "12th Five-Year Plan" period, Yunnan had completed the constructions of 10 professional wild fungi wholesale marketsin Kunming, Yuxi, Chuxiong, Dali, Diqing and other places to establish and improve various types of rural markets and to make the above-mentioned 10 markets become the main distribution centers of wild fungi' fresh products so as to develop and regulate the sale of wild edible fungi (Yunnan Provincial Department of Agriculture, 2016). There has been a significant growing trend in the domestic sales since then. In 2015, the domestic sales volume of the wild edible fungi in Yunnan had reached up to 83 thousand tons with the total sales amount of 7.82 billion Yuan, increased by 70.4\% and 91.6\% respectively compared with 2011 (Research Group of Wild Edible Fungi in Yunnan, 2016). In an investigation on the types of commercial fungi in Yunnan conducted, Wang and Liu (2002) found that there were a total of 207 species and 64 genera had entered into the market, including Boletus sp., Tricholoma sp., Theitphora sp., Russula sp., Lactarius sp., Ramaria sp. and other dominant species which accounted for $80 \%$ of the total trade volume. $29.6 \%$ of the total wild fungi products in Yunnan were for exports, including five continents as well as 20 countries and regions. During the "12th Five-Year Plan" period, the wild fungi export trade had showed a growth trend with a slightly decline in the trade income. In 2015, the total volume of foreign trade of wild edible in Yunnan had reached 11 thousand tons, earning 0.1 billion dollars of foreign exchanges. At the same time, the trade volume and the total trade amount had increased by $37.2 \%$ and had decreased by 22.0\% respectively compared to 2011 (Research Group of Wild Edible Fungi in Yunnan, 2016). Moreover, there were still dozens of bulk products can be available for exports, including Dictyophora, Tremella aurantialba, Termitomyces albuminosus, Chanterelles, Cordyceps sinensis, Ganoderma lucidum, Armillaria, Hericium erinaceus, Lyophyllum, Boletus badius, and Clavariaceae (Song, 2002). From the aspect of types of export products, there were Tricholoma matsutakes, Boletus, Lentinula edodes, straw mushrooms, fungus, Flammulin avelutipes, truffles and other Agaricaceae, and among them: Boletus, truffles and Agaricaceae 
belonged to the large bulk products, accounting for $33.7 \%, 26.8 \%$ and $17.8 \%$ of the total trade volume respectively, and Tricholoma matsutakes, Boletus and trufflesbelonged to the main foreign exchange earning products, accounting for $33.6 \%, 31.3 \%$ and $18.7 \%$ of the total foreign exchange earnings respectively (Research Group of Wild Edible Fungi in Yunnan, 2016). From the aspect of types of export products, there were fresh products, frozen goods, salted products, dried products, cans and other product types, whose export volumes accounted for $25.9 \%, 27.4 \%, 24.6 \%, 16.0 \%$ and $3.5 \%$ of the total trade volume and foreign exchange earnings accounted for $36.2 \%, 14.8 \%, 13.9 \%, 33.3 \%$ and $1.8 \%$ of the total trade amount respectively (Research Group of Wild Edible Fungi in Yunnan, 2016).

Table 1. Production and exchange earning of main edible fungi in Yunnan from 2011 to 2015

\begin{tabular}{|c|c|c|c|c|c|c|c|}
\hline Year & & & 2011 & 2012 & 2013 & 2014 & 2015 \\
\hline \multirow[t]{2}{*}{ T. matsutake } & Quantity & (Ton) & 763.8 & 964 & 781.3 & 708.1 & 432.4 \\
\hline & Exchange earning & (Ten thousand dollar) & 5751.9 & 4858 & 4058 & 3833.2 & 2455.0 \\
\hline \multirow[t]{2}{*}{ B. edulis } & Quantity & (Ton) & 12431 & 9143 & 7708 & 7041.3 & 8366 \\
\hline & Exchange earning & (Ten thousand dollar) & 9178 & 6675 & 5921 & 4852 & 4965 \\
\hline \multirow[t]{2}{*}{ L. edodes } & Quantity & (Ton) & 1022.3 & 428.7 & 1381.3 & 400.1 & 881.2 \\
\hline & Exchange earning & (Ten thousand dollar) & 454.8 & 176.2 & 1346.9 & 676.3 & 1192 \\
\hline \multirow[t]{2}{*}{ F. velutipes } & Quantity & (Ton) & 98.5 & 133.1 & 373.6 & 71.7 & 152.7 \\
\hline & Exchange earning & (Ten thousand dollar) & 20.9 & 18.2 & 25 & 6.8 & 25.0 \\
\hline \multirow[t]{2}{*}{ V. volvacea } & Quantity & (Ton) & 1.1 & 54.9 & 221.6 & 340.5 & 333.1 \\
\hline & Exchange earning & (Ten thousand dollar) & 0.1 & 3.0 & 22.2 & 39.0 & 42.0 \\
\hline \multirow[t]{2}{*}{ Truffle } & Quantity & (Ton) & 3012.9 & 1175.4 & 2256.3 & 2813.3 & 2432.1 \\
\hline & Exchange earning & (Ten thousand dollar) & 2027.2 & 923.5 & 1832.5 & 2263.6 & 1938.0 \\
\hline \multirow[t]{2}{*}{ Exidia auricula } & Quantity & (Ton) & 26.2 & 61.6 & 76.5 & 410.2 & 308.5 \\
\hline & Exchange earning & (Ten thousand dollar) & 30.4 & 94.5 & 115.9 & 761.7 & 527.0 \\
\hline \multirow[t]{2}{*}{ Other } & Quantity & (Ton) & 1949.3 & 751.5 & 1504.2 & 1309.4 & 2253.2 \\
\hline & Exchange earning & (Ten thousand dollar) & 629.2 & 240.4 & 349.0 & 457.4 & 597.0 \\
\hline \multirow[t]{2}{*}{ Total } & Quantity & (Ton) & 7917.6 & 3088.5 & 12289.3 & 9460.0 & 10865.6 \\
\hline & Exchange earning & (Ten thousand dollar) & 12271.8 & 2666.5 & 12547.5 & 10948.6 & 9571.0 \\
\hline
\end{tabular}

Data sources: Kunming customs.

Table 2. Export quantity and exchange earning of edible fungi product in Yunnan

\begin{tabular}{llllllll}
\hline Year & & 2011 & 2012 & 2013 & 2014 & 2015 \\
\hline Fresh product & Quantity & (Ton) & 2402.9 & 1113.5 & 3210.2 & 1363.5 & 3197.3 \\
& Exchange earning & (Ten thousand dollar) & 6140.5 & 262.9 & 4157.7 & 3669.1 & 3130.0 \\
Frozen product & Quantity & (Ton) & 100.1 & 17.1 & 4984.4 & 3083.9 & 3774.0 \\
& Exchange earning & (Ten thousand dollar) & 178.3 & 29.7 & 2946.3 & 1945.2 & 2019.0 \\
\multirow{5}{*}{ Salted product } & Quantity & (Ton) & 3154.9 & 1132.7 & 2088.1 & 3103.3 & 2377.8 \\
& Exchange earning & (Ten thousand dollar) & 1725.6 & 656.5 & 1143.9 & 1714.1 & 1449.0 \\
Dried product & Quantity & (Ton) & 1381.6 & 725.2 & 1919.6 & 1435.2 & 1510.8 \\
& Exchange earning & (Ten thousand dollar) & 3980.3 & 1634.6 & 4077.2 & 3339.4 & 2945.0 \\
Canned product & Quantity & (Ton) & 878.1 & 99.9 & 82.8 & 470.2 & 6.7 \\
& Exchange earning & (Ten thousand dollar) & 247.3 & 82.8 & 219.3 & 277.9 & 28.0 \\
\multirow{3}{*}{ Other } & Quantity & (Ton) & 0.0 & 0.0 & 4.2 & 3.8 & 0.0 \\
& Exchange earning & (Ten thousand dollar) & 0.0 & 0.0 & 3.2 & 3.0 & 0.0 \\
Total & Quantity & (Ton) & 7917.6 & 3088.5 & 12289.3 & 9460 & 10866.6 \\
& Exchange earning & (Ten thousand dollar) & 12271.8 & 2666.5 & 12547.5 & 10948.7 & 9571.0 \\
\hline
\end{tabular}

Data sources: Kunming customs. 
Table 3. Domestic sales and export trade of edible fungi in Yunnan

\begin{tabular}{|c|c|c|c|c|c|c|}
\hline \multirow[b]{2}{*}{ Year } & \multicolumn{2}{|c|}{ Domestic sales } & \multicolumn{2}{|c|}{ Export trade } & \multicolumn{2}{|c|}{ Total } \\
\hline & $\begin{array}{l}\text { Sales Quantity } \\
\text { (Ten thousand tons) }\end{array}$ & $\begin{array}{l}\text { Revenue } \\
\text { (Ten thousand dollar) }\end{array}$ & $\begin{array}{l}\text { Sales Quantity } \\
\text { (Ten thousand tons) }\end{array}$ & $\begin{array}{l}\text { Revenue } \\
\text { (Ten thousand dollar) }\end{array}$ & $\begin{array}{l}\text { Sales Quantity } \\
\text { (Ten thousand tons) }\end{array}$ & $\begin{array}{l}\text { Revenue } \\
\text { (Ten thousand dollar) }\end{array}$ \\
\hline 2011 & 4.4 & 54969.6 & 0.8 & 12271.8 & 5.2 & 67241.4 \\
\hline 2012 & 5.7 & 76643.8 & 0.3 & 2666.5 & 6.0 & 79310.3 \\
\hline 2013 & 5.8 & 81015.7 & 1.2 & 12547.5 & 7.0 & 93563.2 \\
\hline 2014 & 7.1 & 86465.1 & 0.9 & 10948.7 & 8.0 & 97413.8 \\
\hline 2015 & 7.5 & 105371.5 & 1.1 & 9571.0 & 8.6 & 114942.5 \\
\hline
\end{tabular}

Data sources: Kunming customs.

\section{Problems in Wild Edible Fungi Resource Conservation}

\subsection{Resource Reduction}

Yunnan is rich in wild edible fungi resources, but the problem of resource degradation has become more serious recently. Zang et al. (2005) argued that Paxillus ynnanensis and P. rhyticophyllus may become extinct after 1870s. Generally speaking, there are many reasons for the declines of wild edible fungi resources. In the first place, a large number of studies have shown that the unscientific utilization of wild edible fungi resources is the main cause of the decline of wild edible fungi resources, which include: Firstly, disorder collection: the ownership awareness on the wild fungi resource is not in place, which leads to the situation where everyone can collect and utilize the wild fungi without conservation; Secondly, predatory collection: the people tend to collect whatever in sight regardless of the size of the wild fungi, which results in a serious damage to the soil mycelial structure as well as brings about the adverse impact on theyield; Thirdly, destructive collection: use tools such as sickle and hoe to dig the soil and pick the Tricholoma matsutake, Termitomyces albuminosus, Poriacocos and other wild edible fungi without covering the humus soil, which seriously damages the natural wild natural habitat; Fourthly, unprotected utilization: woodland grazing, woodland trampling, woodland cutting, deforestation and other phenomena on the destruction of wildlife habitat resources occur occasionally (Emkly, 1998; Yang et al., 2006; Xiong, 2009). In the second place, Zang et al. (2005) argued that habitat destruction was a factor in the decline of wild fungi resources. Moreover, Yang et al. (2011) also found that the habitat degradation could result in the reduction in the types and numbers of edible fungi. Furthermore, the yield of wild edible fungi could be affected by the temperature, illumination, humidity, rainfall and other climatic factors, and the extreme weather events such as drought could also affect the yield of wild edible fungi at the same time (Lu et al., 2015). Last but not least, the wild edible fungi were correlated with the stand structure, canopy density, and humus soil distribution ( $\mathrm{Su}, 2005)$. The forest fire and other intensity disturbances may change the stand structure, canopy density and humus soil distribution, which may also lead to the resource succession of the wild edible fungi (Zhang \& Hu, 2002).

\subsection{Technical Bottleneck}

The development, utilization and conservation of wild edible fungi resources in Yunnan are faced with many technical problems. Firstly, poor production technology: Despite the abundant wild fungi resources in Yunnan, only $5.7 \%$ of the total resource types can be utilized to realize the artificial cultivation or imitating wild cultivation, and there are still more than 150 species are expected to be cultivated through artificial method or imitating wild condition (Su et al., 2006; Luo et al., 2011). For 94.3\% of the pure wild species, there are few techniques for the artificial production and there exists large difficulty in controlling natural yield on one hand. On the other hand, the collection capacity is relatively weak. The collection is carried out intensively in the area which is easy to collect the wild edible fungi rather than in the area that is difficult to collect the wild edible fungi. Meanwhile, the collection is carried out intensively on the wild fungi with high economic value rather than on the wild fungi with low (none) economic value, which not only waste a large amount of resources but also destroy the resource environment (Li, 1989; Yang et al., 2006). Secondly, weak deep processing: Viewing from the export data, the export products in Yunnan are focused on the fresh products, frozen products, salted products, dry products and other raw materials products, accounting for only $3.5 \%$ of total exports for the cans and other primary products (Research Group of Wild Edible Fungi in Yunnan, 2016). Developing drugs, flavoring agents and cosmetics by adding the extraction from the functional components in the fermentation mycelium is a new idea for the development of pure wild species. However, due to the restrictions on the industrialization development brought about by the low content of active substances in fermentation mycelium 
as well as the high extraction cost and other technical problems, the industrial production is scarce although some progress have been made in the researches on the cross breeding, mutation breeding and protobiont fusion technology (He et al., 1997; Li et al., 2004; Luo et al., 2011). In addition, there are still 40 thousand tons of wild edible fungi stalks, defective goods, debris and other residues left to be unprocessed and unused (Liu et al., 2016). Thirdly, low scientific and technological levels: As a type of food resource, wild edible fungi is mostly in the form of the fresh product. Therefore, appropriate frozen and fresh preservation measures shall be taken in the collection, purchase, storage, transportation and sale processes, drying, salting, frying and other methods shall be used to extend the shelf life, while the simple and rough processing technology not only can not improve the value of wild edible fungi but also can result in the decay and loss of nutrition in edible fungi easily (Xiong, 2014; Su, 2011). As a type of health food resource, the processing level of wild edible fungi is low, the majority of the products are the slice drying, broken and crushed granulation products while the processed products with the functional active substance extractions are less (Zhang, 1994; Xu \& Gui, 1998; Luo et al., 2011). As a type of drug resource, wild edible fungi has the potential in the developments of antibiotics, anti-tumor drugs and biological pesticides. However, the drug processing related to the wild edible fungi is still in the research stage with low commercialization level, and some product function factors are still not clear, which bring about a huge difficulty in the control on the product quality. Moreover, some studies also found that the wild edible fungi possesses the anti-aging active ingredients, which can be utilized as the raw materials for cosmetic processing in the future although the developments of the facial mask, emulsion (cream) as well as other skin cares, whitening and anti wrinkle products are still in the development stages (Xiong, 2014). In addition, the processing residues of the wild edible fungi have the potential to develop the organic fertilizer and feed though relevant researches in Yunnan are still in the experimental research stages (Liu et al., 2016). Fourthly, less protective measures: There are only 3 fungi species listed as protected species, which are Tricholoma matsutake (IIgrade), Cordyceps sinensis (IIgrade) and Polyporus umbellatus (III grade) (list of protected plants and list of protected wild medicinal plants). However, there are still many endangered species which receive insufficient attentions currently. In addition to legislative conservation, what's even more important is to establish the natural reserve in order to protect the habitat resources.

\subsection{Management Challenge}

The government departments involved in the conservation of wild edible fungi resources in Yunnan are mainly the Provincial Supply and Marketing Cooperative, the Provincial Department of Agriculture and the Provincial Forestry Department while the unified deployment and coordination between different are absent in the practical works. As adirect manager of wild edible fungi resource conservation, the management challenge is highlighted due to the inadequate manpower, narrow management coverage, poor treatment, weak management motivation, low education level and lack of management skill in the ranger post. According to the Forest Law and China's Forest Law Implementation Regulations, it is specified that the wild edible fungi shall be owned by the person with the forest right or land contract management right as a type of natural resource. However, relevant laws and regulations have not specified the punishment rules on the illegal activities such as stealing and destructing wild edible fungi resource, thus lacking legal basis for the conservation and management of wild edible fungi resources ultimately (Yang et al., 2006).

\section{Dominant Views on Utilization and Conservation of Wild Edible Fungi Resource}

\subsection{On Policies and Regulations}

The government is duty-bound to realize the sustainable development of wild edible fungi industry. Firstly, the state shall improve the existing law and regulation systems, clear the ownership of wild edible fungi resources, develop the punishment rules, standardize the production, processing, management and conservation activities in relations to the wild edible fungi, and protect peasants'ownership interests at the same time. The practices have showed that clearing ownership is beneficial to raise the enthusiasms of peasants to participate in the resource conservation and the sustainable utilization of wild edible fungi resources. Taking Xiaoshao Village of Yiliang Country of Yunnan Province as an example, the wild edible fungi yield had been raised to 0.1 million tons/year (2006 year) after clearing ownership by changing the collective management mode to the contract management mode of the mountain forest, increased by 200 times compared with the previous 0.01 million tons/year (1993 year) (Meng et al., 2010). Secondly, the government shall timely organize the relevant professionals to conduct the general surveys on the wild edible fungi resources, prepare the list of protected wild fungi species, divide the special nature reserve for the wild edible fungi and develop the scientific conservation programs, which have an extremely strong practical significance on the sustainable development of wild edible fungi industry. Relevant researchers have found that the determining the protected species serves as the basis for the scientific conservation and utilization of wild specie resources. Moreover, the establishment of nature reserves for the wild 
edible fungi is one of the important measures to reserve the diversity of national specie resources. Thirdly, establish the professional management team, which is the effective measure for the conservation and utilization of the wild edible fungi resources. Hou and Wei (2002) argued that one of the root causes of the management problems in the nature reserves in China lies in the management system that is coordinated by several departments, which is not disadvantageous for implementing the management system, managing the fund allocation and improving management level, causing the conflict between the protected areaand the local community development eventually. Fourthly, strengthen the constructions of the rural regulations and rules, which is one of the important aspects for the orderly management of wild edible fungi resources. Taking Fawo Village of Wuding Country as an example, based on the rural regulations and rules, the peasants were only allowed to collect the wild edible fungi on the self-owned forest (soil) land and the unauthorized collection in cross-regions were strictly prohibited. In addition, peasants were willing to protect the forest land and grasped the time to collect the mature wild fungi, and the grazing and cutting activities were restricted in the village at the same time. In this way, the wild edible fungi yield in the whole village had been maintained to be between 120 to $140 \mathrm{Kg}$ /year for years. However, the wild edible fungi yield in the whole village had been decreased to 10 $\mathrm{Kg} / \mathrm{year}$ at the beginning of the twenty-first century from $100 \mathrm{Kg} / \mathrm{year}$ in $1990 \mathrm{~s}$ because of the disordered collection of wild fungi of its adjacent Chadian village (Peng et al., 2002).

\subsection{On the Cultivation of Professional Fungi Peasants}

The artificial domestication and cultivation, scientific collection, resource conservation, standardized processing and modern trade activities on the wild edible fungi require strong technicalities. The edible fungi poisoning incident occurs every year in Yunnan, while it is caused by the unscientific acquisition and consumption from the root. Through survey, Wang and Liu (2002) also found that there were still $4 \%$ of poisonous fungi flowing into market in Yunnan, which brought huge hidden security risk on the wild edible fungi consumption; In 2016, Shanxi occurred the incident of illegally bleaching Lentinula edodes using by using fluorescent agent, attracting a lot of attention in society. Therefore, it is extremely urgent to cultivate the professional fungi peasants, which can be achieved by the following two points. On one hand, carry out the professional technical trainings for the peasants with rich practical experiences on the production and collection of edible fungi and separate them from traditional agriculture peasants so as to help them become professional fungi peasants. According to incomplete statistics, there are 5 million edible fungi workers in Yunnan (Yunnan Provincial Department of Agriculture, 2016), showing a desperate demand to enrich and develop the human resources engaged in the edible fungi industry in Yunnan through professional training. On the other hand, encourage the college students who have been studied on relevant trainings systematically to return home or participate in the works related with the conservation and utilization of wild edible fungi resources.

\subsection{On the Development of Artificial Cultivation}

Artificial cultivation is not only one of the utilization form of wild edible fungi resource, but is also an effective method for resource conservation (Su et al., 2006). Meanwhile, the cultivated fungi is not only the exported bulk product, but is also one of the major source of earning foreign exchange, whose export volume accounts for 35.1 to $52.5 \%$ of the total export volume and the foreign exchange earning amount accounts for 20.6 to $45.6 \%$ of the total amount of foreign exchange earnings (Research Group of Wild Edible Fungi in Yunnan, 2016). In addition, the development of wild fungi in imitated wild condition is one of the key technologies for the current wild fungi resource conservation. Through mycorrhizal seedling artificial conservation and breeding technology, not only the survival rates of seedlings can be improved, but also the forest land environment can be protected to the maximize extent and the wild fungi resources can be recovered, achieving the sustainable development in a virtuous circle ultimately (Gao et al., 2015). In addition, the artificial conserved and bred Truffle industries have been successfully formed in France, Italy and New Zealand with certain scales. The two-year truffleseedling can be sold at the price of 40 dollars/plant (Song, 2002).

\subsection{On the Promotion of Deep Processing}

Deep processing can improve the product price significantly. The economic value of salted Boletus edulis exported to Italy can be added more than ten times after desalted and processed into cans; The C-class product of Boletus edulis can be sold at the price of 5 to 6 dollars/Kg in Yunnan, while it can be sold at the price up to 200 dollars/Kg in Japan after sorted and packaged, increasing more than 50 times of it original value (Zhang, 1994); The produced Ganoderma lucidum slice can be sold at only about 93 dollars $/ \mathrm{Kg}$, the produced spore powder capsulecan be sold at the price up to 1400 dollars $/ \mathrm{Kg}$, and the polysaccharides can be sold at the price up to 1500 to 2000 dollars/Kg (Gong et al., 2007). Therefore, deep processing is the direction for developing the edible fungi industry in the future. Viewing from the aspect of food, it is appreciate to innovate the specialized 
preservation technology and the storage technology to extend the shelf lives of the productsand to promote the development of functional foods; Viewing from the aspect of drug, it is appreciate to develop the antibiotics, anti-tumor, liver-protection, stomach trouble treatment, anti-aging drugs or cosmetics and other products whose functional factors are clear. Viewing from the aspect of comprehensive utilization, there are considerable good market prospects and huge development potentials in the developments of edible fungi feed processing, edible fungi biological fertilizer as well as the biological pesticides.

\subsection{On the Implementation of Standardized Trade}

In the saleand trade processes, due to unequal information and technology, some traders or countries may implement the trade monopolies or technical barriers to gain the monopoly profits or technical profits, seemingly profitable, while it directly influences the enthusiasms of the fungi peasants to be involved in the conservation and utilization activities of wild edible fungi resources actually. Moreover, it further influences there-investment amount, which can cause a fatal injury on the wild mushroom industry chain. Therefore, it is appropriate to expanse the sale channels and establish the specialized online and offline sales network in order to break the trade monopoly; Meanwhile, it is also appropriate to strengthen the exchange and cooperation to prohibit the technical barriers and to regulate the wild fungi product trade. In addition, the traditional idea that there is no food safety problem for the naturally grew wild fungi, while the fact is that the wild edible fungi pesticide residue and the excessive heavy metal problem may exist in the wild edible fungi due to the chemical pesticide pollution as well as the high contents of heavy metals in the habitat environment. Although no wild edible fungi pesticide residue accident has been foundin Yunnan, a large number of studies have found that the excessive heavy metals such as lead, arsenic, cadmium, lead, mercury and other heavy metals occurred in Yunnan occasionally due to the high contents of heavy metals in the environment (Xu et al., 2011; Yang et al., 2015; Zhang et al., 2011; Huang et al., 2011). At the same time, the illegal uses of fresh-keeping agents, preservatives, whitening agents, fumigant agents may also bring about food safety problems in the processingprocess, such as: the Trichototma matsutake exported to Japan in 2012 were largely reduced due to excessive dichlorvos; the Boletus exports to Europe was detained for excessive $\mathrm{SO}_{2}$ (Wu et al., 2010). Therefore, it will be of positive significances to actively developand implement the technical standards for production and processing of edible fungi and to regulate the edible fungi product market for the future development of edible fungi industry.

\section{Perspectives}

In summary, a lot of researches on the current situation, conservationand utilization of the wild fungi resources in Yunnan have been carried out successively. Based on the past researches as well as the current situation and problems of the resource conservation and utilization, we put forward the following views on how to carry out the effective conservation and sustainable utilization of wild edible fungi resources in Yunnan.

Firstly, viewing from the aspect of policies and regulations, the state has formulated and promulgated a number of policies and regulations related to the conservation of forest resourcesin recent years, while there are no special policies and regulations on the conservation and sustainable utilization of forest resources such as wild edible fungi in the existing policies and regulations. We believe that the most important matter is to clear the ownership of wild edible fungi resources in these existing policies and regulations. Only by clearing the ownership and other issues as well as protecting the interests of community peasants can they be really concerned about the conservation and sustainable utilization of the wild edible fungi resources as well as be actively involved in the conservation and sustainable utilization actions. Therefore, clearing ownership plays an important role in raising the enthusiasms of peasants to participate in the conservation and the sustainable utilization of wild edible fungi resources, which shall be considered as the policy issue on the effective conservation and sustainable utilization of wild edible fungi resources attached with great importance.

Secondly, several developed countries in Europe and the United States have carried out a large number of researches and practical explorations on the bio-diversity as well as the conservation and utilization of resources. Fromthe experiences of foreign countries, the community-based bio-diversity and resource conservation strategies are the most effective ways and approaches to solve the contradictions between the existing community economic development and the resource conservation as well as utilization. Generally speaking, the key of community-based conservation strategy is to highlight the dominant role of peasants and the interest sharing mechanism in the community conservation. As one type of shared resources and wealth, the wild edible fungi shall benefit all peasants in the community. Through raising the subject consciousness in community peasants to jointly participate in the conservation, solving the interest sharing issue in the community, as well as establishing the rural regulations and rules on the resource conservation and sustainable utilization, the conservation and utilization behaviors in relations to wild edible fungi resources in the community can be 
constrained and regulated, and the effective conservation and sustainable utilization of the edible fungi resources in the community can be further realized eventually. However, there are a lot of imperfections in the relevant works judging from the present domestic situation. Therefore, it will be the most effective approach to strengthen the practices on the community-based conservation and utilization in order to protect and make great use of the wild edible fungi resource in a sustainable way in the future.

Thirdly, it is also important to develop the technical methods and measures on the sustainable utilization and conservation of wild edible fungi resources. The scientific research institutes shall focus on the current problems in the artificial collection, resource conservation and other processes of wild edible fungi resources in order to actively explore and popularize the more scientific and reasonable collection methods, artificial domestication and cultivation, artificial conservation and breeding as well as other technologies. In addition, enterprises shall focus on the weak point in the edible fungus industry development to research and develop the food preservation technology and deep processing technology, explore the medicinal and health values in the wild edible fungi, extract the functional substances in the mycelium fermentation, develop the drugs and health products with clear compositions, actively expand the bulk market and make efforts to raise the resource value of wild edible fungi.

Fourthly, the wild edible fungi pesticide residues, excessive heavy metals and food safety issues shall also be given more attentions, especially the researches on the causes of pesticide residues and excessive heavy metal as well as the corresponding technology to solve these problems.

In conclusion, we believe that the above-discussed four issues are of crucial importance, which are not only related to the effective conservation and sustainable utilization of wild edible fungi resources but is also associated with the coordinated development between the rural community economy and the bio-diversity as well as the forest conservation.

\section{References}

Chen, Y., An, K., \& Zhang, H. (2010). Biodiversity and outlook in Yunnan province. Shandong Forestry Science and Technology, 187(2), 100-103.

Dai, Y. C., Tu, L. G. E., Cui, B. K., et al. (2013). Illustrations of medicinal fungi in China. Harbin: Northeast Forestry University Press.

Emkly, Y. (1998). The importance of non-wood forest products - Collection and trade of matsutake in Yunnan province. Forestry and Society Journal, 1, 15-16.

Gao, J., Huang, W., Li, R. C., et al. (2015). Boosting Yunnan plateau characteristic agriculture by scientifically developing the industry of returning ecological edible mushrooms. Edible Fungi of China, 34(2), 77-81.

Gong, M. Q., Zhong, C. L., Chen, Y., et al. (2007). Mycorrhizal edible fungi and its semi-artificial cultivation. Guangzhou: Guangdong Science and Technology Press.

Gui, M. Y., \& Xu, J. (1999). Prospects of exploitation and utilization on edible fungi resource in Yunnan. Edible Fungi of China, 18(1), 5-7.

He, J. C., Huo, Y., \& He, Y. X. (1997). Plurisporous crossbreeding of Auricularia polytricha and A.auricula-judae. Edible Fungi, $19(3), 8$.

Hou, Y. S., \& Wei, G. (2002). The Problems and Causes in Natural Reserves Management. Journal of Beijing Forestry University (Social Sciences), 1(4), 42-47.

Huang, C. Y., Chen, Q., \& Zhao, Y. Z., et al. (2010). Investigation on heavy metals of main wild edible mushrooms in Yunnan province. Science Agriculture China, 43(6), 1198-1203.

Jia, L. R. (2003). Forest biodiversity of Yunnan province and its environmental value assessment. Forest Inventory and Planning, 28(3), 84-90.

Li, S. Y., Li, M. L., Hu, C. X., et al. (2004). The techniques of intraspecific protoplast isolation and fusion crossbreeding in Pleurotus ostreatus. Letters in Biotechnology, 15(6), 580-583.

Li, Y. X. (1989). The thinking about exploitation and management of edible fungi of Yunnan. Edible Fungi of China, 4(31), 41-42.

Liu, J., Wang, G. Y., \& Chen, Z. B. (2016). Main nutrients of five kinds of byproducts of wild edible mushrooms in Yunnan. Journal of Food Safety and Quality, 7(9), 3767-3772.

Lu, X., Jin, Y. L., \& Wang, Z. H. (2007). Mountain forest resources in the undergrowth and the livelihood of farmers - A case study of Chuxiong prefecture in Yunnan province. Forestry Economics, 8(16), 74-76. 
Lu, Y. X., Tian, H. M., Yang, H. S., et al. (2015). Characteristics of climate habitats of edible wild fungi in Yunnan province. Chinese Journal of Eco-Agriculture, 23(6), 748-757.

Luan, B., Li, R., \& Yang, R. (2010). The development strategy based on SWOT mode about Yunnan edible mushroom industry. Reformation \& Strategy, 26(10), 59-62.

Luo, X., Jiang, N., Wei, W., et al. (2011). Research status and development direction of medicinal fungi in China. Edible and Medicinal Mushrooms, 19(1), 6-9.

Meng, X. J., Lai, Q. K., \& Xie, H. S. (2010). Management model for sustainable exploitation of wild edible fungi resources-A case study of Xiaoshao village at Yiliang county, Yunnan province. Resource Development \& Market, 26(3), 238-241.

Mirian, D. R. (2010). The contribution of wild fungi to diet, income, and health: A world review. In R. Mahendra \& K. George (Eds.), Progress in mycology. India: Scientific Publishers. https://doi.org/10.1007/978-90-4813713-8_12

Pavel, K. (2009). Chemical composition and nutritional value of European species of wild growing mushrooms: A review. Food Chemistry, 112, 9-16. https://doi.org/10.1016/j.foodchem.2008.07.077

Peng, Y. G., Sheng, X. L., \& Zhang, Y. G. (2002). Utilizationof wild edible fungi resources and income of mountain community farmer household-Case study on Chadian town, Wuding county, Yunnan province. Forestry Economic, 6(21), 28-30.

Research Group of Wild Edible Fungi in Yunnan. (2016). Research report on wild edible fungi industry development in Yunnan.

Song, D. S. (2002). An analysis on the domestic and abroad markets prospect of wild edible fungi and the position of Yunnan edible fungi. Journal of Southwest Forestry College, 22(3), 33-38.

$\mathrm{Su}$, E. G. (2011). Resources status and industry development of wild edible fungi of Yunnan. Rural Economy and Science-Technology, 22(6), 26-27.

$\mathrm{Su}, \mathrm{K}$. M. (2015). Investigation of truffles ecology in Yongren county, Chuxiong city, Yunnan province. Edible Fungi of China, 24(4), 12-13.

$\mathrm{Su}$, K. M., Yu, F. Q., Wei, J., et al. (2006). Prospects of diversity and exploitation on saprobic edible fungi resource in Yunnan. Edible Fungi, Supplementary Issue, 15-18.

Tong, Q. (2010). Resources and ecological distribution of wild edible mushrooms in Pu'er of Yunnan. Edible Fungi, 1, 14-16.

Wang, H. J. (2001). Medicinal and hygienic value of edible fungi. Edible Fungi, 3, 41-42.

Wang, X. H., \& Liu, P. G. (2002). Resources investigation and studies on the wild commercial fungi in Yunnan. Biodiversity Science, 10(3), 318-325.

Wang, X. M., Zhang, J., Wu, L. H., et al. (2014). A mini-review of chemical composition and nutritional value of edible wild-grown mushroom from China. Food Chemistry, 151, 279-285. https://doi.org/10.1016/ j.foodchem.2013.11.062

Wu, S. X., Luo, X. L., Liu, P., et al. (2010). Analyse and advise to research and development of wild edible fungi. Food Science and Technology, 35(4), 100-103.

Xiong, Y. S. (2014). Studies on strategies and countermeasures of Kunming wild edible fungi resource protection and utilization. Beijing: Graduate School of Chinese Academy of Agricultural Sciences.

Xiong, Z. (2009). Conservation of wild edible fungi resources of Yunnan. Beijing: Newspaper of the Chinese People's Political Consultative Conference.

Xu, D. X., Lin, J., Wan, Y. P., et al. (2011). Detection and analysis of cadmium content of common wild edible fungi from Yunnan province. Chinese Journal of Health Laboratory Technology, 21(3), 705-707.

Xu, J., \& Gui, M. Y. (1998). Utilization and conservation of edible fungi in Yunnan province. Modern Business Trade Industry, 10(11), 44.

Xu, M. L., Qu, Y. C., He, M. Q., et al. (2014). Investigation on the relationship between wild edible mushroom and farmers income in Yimencounty. Edible Fungi of China, 33(6), 62-66.

Yang, T. W., Zhang, J., Jerzy, F., et al. (2015). Mercury concentration in common Boletus fungi from Yunnan Province and ingestion safety assessment. Chinese Journal of Ecology, 34(12), 3518-3525. 
Yang, X., Lang, N. J., Liu, X. F., et al. (2011). Study on difference of edible fungi and soil microorganism in different degraded mountainous areas. Edible Fungi of China, 30(3), 15-17.

Yang, X.., He, J., Li, C., et al. (2008). Matsutake trade in Yunnan province, China: An overview. Economic Botany, 62(3), 269-277. https://doi.org/10.1007/s12231-008-9019-6

Yang, Y. H., Su, K. M., Wang, Z. H., et al. (2006). Discussion about strategies for management and protection of wild mushroom resources in Chuxiong prefecture. Journal of West China Forestry Science, 35(3), 154-158.

Yu, F. Q., \& Liu, P. G. (2005). Species diversity of wild edible mushrooms from Pinus yunnanensis forests and conservation strategies. Biodiversity Science, 13(1), 58-69. https://doi.org/10.1360/biodiv.040129

Yu, F. Q., \& Liu, P. G. (2013). Wild edible and medicinal mushrooms in Pu'er of Yunnan and their sustainable utilization. Journal of Fungal Research, 11(1), 14-23.

Yu, F. Q., Wang, X. H., \& Liu, P. G. (2002). Prospects of exploitation and utilization on edible fungi resource in Yunnan. Chinese Wild Plant Resources, 21(4), 21-25.

Yunnan Provincial Department of Agriculture. (2016). The "13th Five-Year Plan" of industrial development of edible fungi in Yunnan.

Zang, M., Li, X. J., \& Zhou, Y. K. (2005). Biodiversity and resources conservation of edible fungi of Yunnan. Edible Fungi of China, 24(6), 3-4.

Zhang, D., \& Zhang, X. S. (2013). System thinking on economic development and biodiversity conservation win-win ways for transforming the pattern of development in forestry. Journal of Systems Science, 21(1), 46-50.

Zhang, G. Y. (1984). Edible fungi of Yunnan. Kunming: Yunnan People's Publishing Press.

Zhang, G. Y. (1994). Foreign exchange earning prospects of Yunnan edible fungi. Edible Fungi of China, 5, 32-37.

Zhang, G. Y. (1999). Illustration for China popular edible mushroom. Kunming: Yunnan Science and Technology Press.

Zhang, M., \& Hu, H. Q. (2002). The effect of forest fire on microorganism in soil. Journal of Northeast Forestry University, 30(4), 44-47.

Zhang, Y. J., Hu, G. H., \& Li, H. C. (2011). Analysis and assessment of heavy metal pollution in fresh edible mushrooms collected from several areas in Yunnan province. Northern Horticulture, 20, 171-174.

Zhao, Y. X., Wu, X. L., \& Huang, S. Z. (2013). Advance on chemical constituents and bioactivity of the medicinal fungi in China. Guizhou Science, 31(1), 18-27.

\section{Copyrights}

Copyright for this article is retained by the author(s), with first publication rights granted to the journal.

This is an open-access article distributed under the terms and conditions of the Creative Commons Attribution license (http://creativecommons.org/licenses/by/4.0/). 